\title{
An Investigation Into The Sintering Of Magnesium Fluoride Optical Material By Microwave
}

\author{
Shangzhao Shi, Jiann-Yang Hwang, Bowen Li, Xiaodi Huang \\ Michigan Technological University \\ Houghton, MI 49931
}

\begin{abstract}
:
The presented work was an investigation on the sintering of magnesium fluoride with microwaves. The sintering was conducted in a 2.45-GHz microwave applicator under an argon atmosphere. Sintering shrinkage and density were measured. The microstructure of the sintered samples was examined. Feasibility and advantages regarding microwave sintering of magnesium fluoride were discussed.
\end{abstract}

\section{Introduction}

Magnesium fluoride is an optical material utilized in fabrication of infrared transmission windows. The conventional techniques to produce magnesium fluoride ceramics include single crystal growth ${ }^{1}$, pressureless sintering ${ }^{2}$, hot pressing ${ }^{3}$ as well as hot isostatic pressing ${ }^{4}$. Microwave sintering is a volumetric and fast densification technique, and has demonstrated many advantages in ceramics sintering. This method, however, has not been attempted in the sintering of Magnesium fluoride. The presented study is the first reported attempt of microwave sintering of the $\mathrm{MgF}_{2}$ ceramics.

\section{Experimental}

As-received $\mathrm{MgF}_{2}$ powder was calcinated in argon at $600^{\circ} \mathrm{C}$ for 2 hours and then ground with a mortar to pass a 325-mesh screen. The ground powder was mixed with $2 \%$ gum as binder. Distilled water of appropriate amount was added to the binder to develop strength. Uniaxial compacting was performed with a steel die of 0.5 inch in diameter, and the compaction pressure was 5000 psi. The disk dimensions were $\phi^{1 / 2}{ }^{\prime \prime} \times 1 / 4$ ".

Microwave sintering was performed with a 4-kW microwave furnace. $\mathrm{MgF}_{2}$ disks were placed at the center of the hot chamber surrounded by SiC susceptors. Zirconia beads were placed on the bottom of the chamber, in order to avoid possible reactions of the refractory insulation with the specimen as well as the SiC susceptor. A k-type thermocouple was used to measure the chamber temperature. The distance from the specimen top to the thermocouple tip was $1 / 2$ ".

The hot chamber of the furnace was airtight, and had ports to connect a vacuum pump and an argon cylinder. For each run, the chamber was vacuumed and then filled with argon to reach atmospheric pressure. The procedure of vacuuming/argon-filling was repeated several times to ensure complete removal of oxygen. 
The sintering temperature profile was determined with the consideration of binder decomposition, which may otherwise result in collapsing, cracking or other problems. The temperature was controlled with the controller, which is capable of continuously adjusting the microwave power intensity.

The specimen dimensions were measured with a caliper before and after sintering. Linear shrinkage was calculated by comparing of the data. The sintered specimens were weighed. Densities were calculated based on the weight and volume of the sintered specimens. SEM was employed to examine the microstructures.

\section{Results and Discussion}

Fig.1 shows the sintering temperature profile. The shrinkage and density of \#1 and \#2 specimens are given in Table 1.

Compared to the theoretical density (3.18 g. $\mathrm{cm}^{-3}$ ), the densities of \#1 and \#2 specimens are substantially low. Sintering at $1100^{\circ} \mathrm{C}(\# 4)$ and $1075^{\circ} \mathrm{C}(\# 5)$ was therefore attempted in order to improve the density. However, the sintering behavior was so sensitive to temperature, that these two specimens

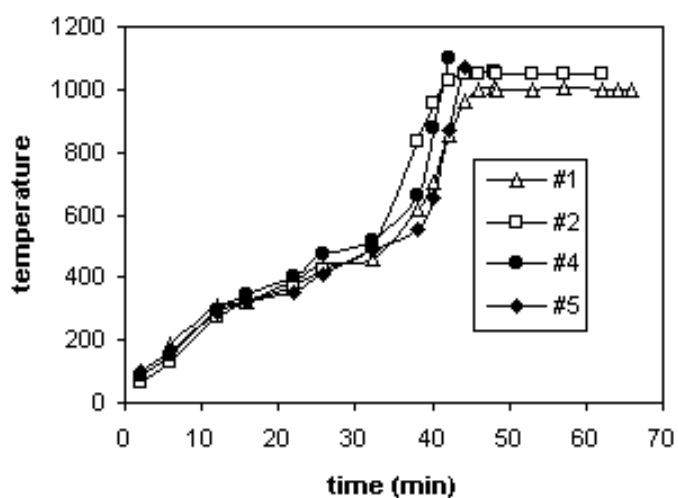

Fig. 1 Tempeture profile for mw sintering of $\mathrm{Mg}_{2} \mathrm{~F}$ were partially melted even though no holding time was used.

Table 1

\begin{tabular}{ccccc}
\hline \multirow{2}{*}{$\begin{array}{c}\text { specimen } \\
\mathrm{s}\end{array}$} & \multirow{2}{*}{$\begin{array}{c}\text { Sintering } \\
\text { conditions }\end{array}$} & \multicolumn{2}{c}{ Shrinkage (\%) } & \multirow{2}{*}{ Density $\left(\mathrm{g} \cdot \mathrm{cm}^{-3}\right)$} \\
\cline { 3 - 4 }$\# 1$ & $1000^{\circ} \mathrm{C} \times 20 \mathrm{~min}$ & -9.79 & -9.70 & 2.22 \\
\hline$\# 2$ & $1050^{\circ} \mathrm{C} \times 20 \mathrm{~min}$ & -11.11 & -11.47 & 2.34 \\
\hline
\end{tabular}

Figure 2 shows the SEM images taken from the $\mathrm{MgF}_{2}$ samples sintered at different temperatures and holding times. Image $a$ and $b$ were taken from sample \# 1 and \#2, respectively. The images indicate that the higher degree of sintering and denser microstructures were achieved when sintering was performed at $1050^{\circ} \mathrm{C}$ for $20 \mathrm{~min}$. The SEM observation is in good agreement with the shrinkage and density measurement as shown in Table 1 . Compared to Image $a$, Image $b$ features straight grain boundaries, less porosity and substantial grain growth. The transgranular cracking indicates the strong bonding between grains had been developed. 

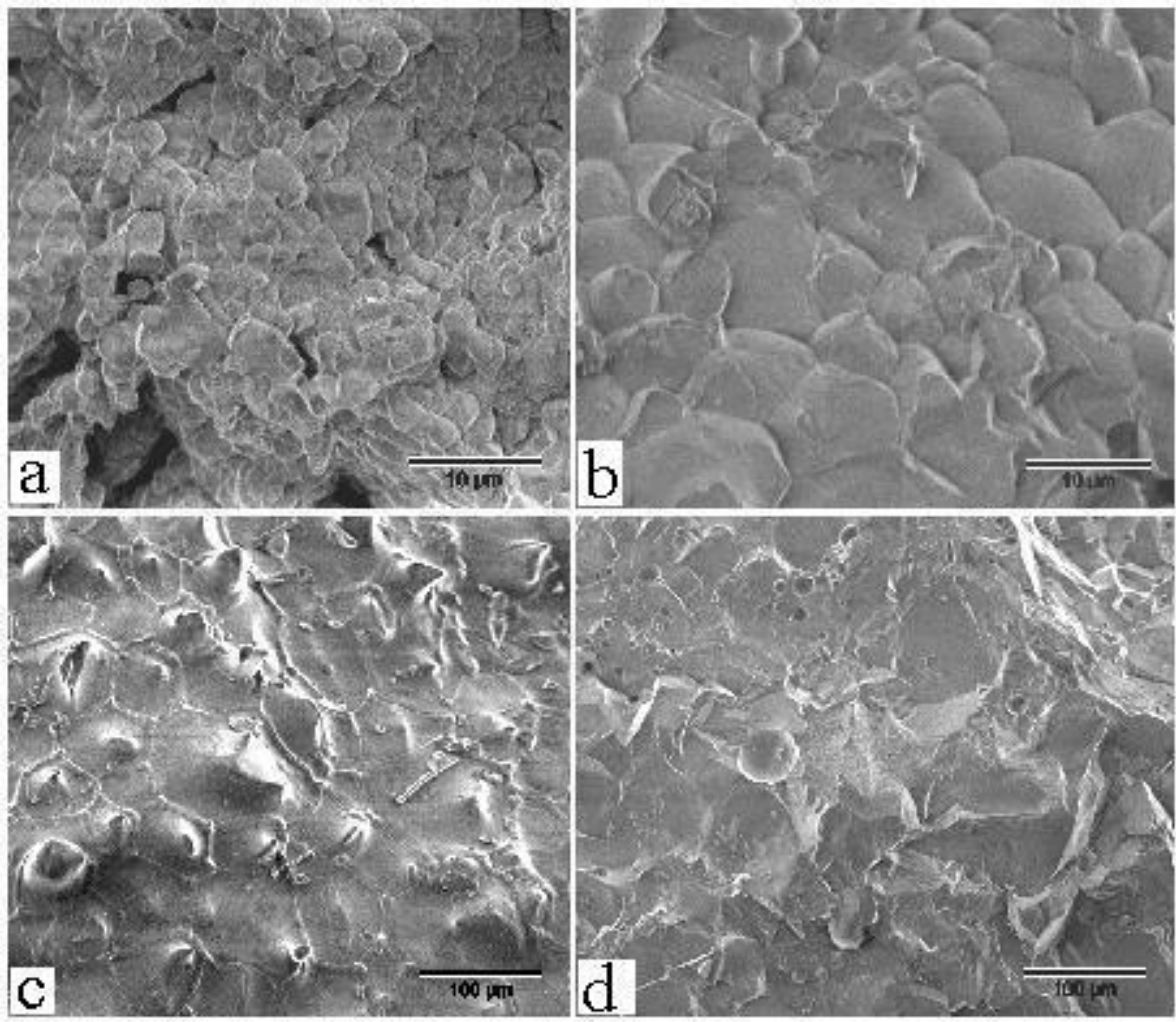

Fig. 2 SEM images taken from the sintered samples. a) $1000^{\circ} \mathrm{C} \times 20$ $\min$; b) $1050^{\circ} \mathrm{C} \times 20 \mathrm{~min}$; c) $1100^{\circ} \mathrm{C}$ without holding time ; d) $1075^{\circ} \mathrm{C}$ without holding time

Image $c$ and $d$ were taken form simple \#4 and \#5, respectively. They indicate substantial liquids formed in sintering at these temperatures. Grains in $d$ have almost lost their shape and merged into a shapeless matrix. Although there are a few distinguishable grains, their shape changed into spherical. Image $c$ reveals a number of craters distributed in the liquid matrix. It indicates gaseous species formed during sintering at $1100^{\circ} \mathrm{C}$. There are also rod-like particles, one of which is shown in higher magnification in Fig.3. Their formation is believed to involve with an evaporation-condensation process.

\section{Conclusions}

Sintering of magnesium fluoride is difficult. We have searched several welldocumented literature databases for microwave sintering of magnesium fluoride, but have found no publication dealing with this subject. Even for conventional sintering, very few references can be found dealing with this subject. It seems that successful microwave sintering of pure $\mathrm{MgF}_{2}$ requires delicate sintering conditions, which needs extensive research. 
The result from this study suggests that the optimum sintering temperature would be $1050^{\circ} \mathrm{C}$. Lowering the sintering temperature would not produce a densified microstructure. Increase the sintering temperature would result in melting. At the optimum sintering temperature, a prolonged holding period seems necessary for higher density. However, structural coarsening appears significant. In order to obtain a fine microstructure while achieving full densification, an additional densification method, such as hot pressing, needs to be added.

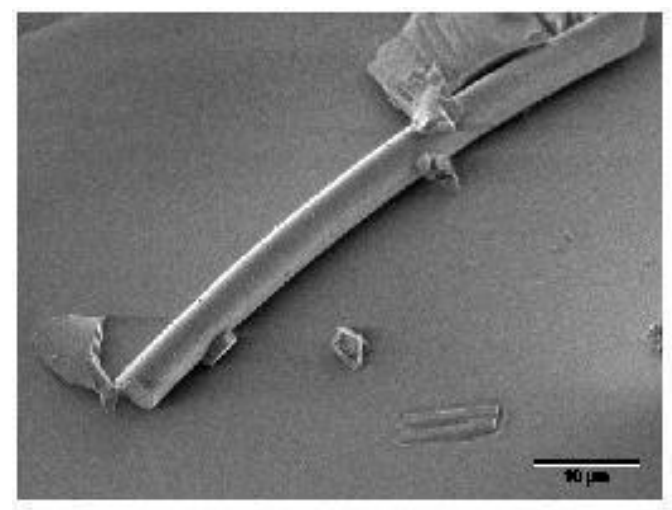

Fig. 3 Rod-like particles appeared in a sample sintered at $1000^{\circ} \mathrm{C}$ without holding time

\section{Reference}

1. Recker, Kurt; Leckebusch, R.; "Vapor phase growth of single crystals of high-melting fluorides. I. Magnesium fluoride”; Journal of Crystal Growth, (1969), 5(2), 125-31.

2. Rice, Hal H.; Garey, Maurice J.; "Sintering of magnesium fluoride"; American Ceramic Society Bulletin, (1967), 46(12), 1149-53.

3. Mal'tsev, M. V.; Udalova, L. V.; Goryachev, A. Ya.; Levina, N. K.; Perminova, N. B.; "Fabrication of optical-ceramic preforms without mechanical treatments"; Opticheskii Zhurnal, (1993), (1), 69-72.

4. Shirakawa, Youichi; Harada, Tamotsu; Sashida, Norikazu; Miyata, Noboru; "Preparation of $\mathrm{MgF}_{2}$ sintered body by normal sintering combined with capsule-free hot-isostatic pressing treatment”, Nippon Seramikkusu Kyokai Gakujutsu Ronbunshi/Journal of the Ceramic Society of Japan, v 107, n 1252, Dec, 1999, p 1137-1139. 